\title{
The effect of eye-like schema on shuttling activity of wild house mice (Mus musculus domesticus): Context-dependent threatening aspects of the eyespot patterns
}

\author{
JÓZSEF TOPÁL and VILMOS CSÁNYI \\ L. Eötvös University, Göd Jávorka, Hungary
}

\begin{abstract}
The effects of footshock and various light-spot models on the shuttling activity of mice were examined in a passive avoidance situation. It was found that mild footshocks elicited initial exploration followed by an increased tendency to escape from the compartment in which the shocks were administered. An encounter with models, consisting of various numbers of small yellow lights, without footshock did not cause significant differences in shuttling activity. But if the models were paired with footshock, a tendency to explore during the first trial, high readiness to escape, and avoidance learning were found. These were characterized by a temporary increase in number of gate crossings, a decrease in the time spent in the shocked compartment, and a considerable increase in latency to enter the shocked compartment. The most effective model had two horizontally arranged yellow lights, which may share some characteristics with eye-like patterns.
\end{abstract}

Defensive behavior systems are commonly thought to be the product of the influence of extremely strong selection pressure upon not only the form of defense, but also the relationship between defensive behavior and the stimuli or situation that elicits this action (R. J. Blanchard, D. C. Blanchard, \& Hori, 1989). In the case of a given species, the functional significance of a pattern of defensive behavior is revealed by an analysis of the interaction between the dynamics of behavior and the ecological system to which the species has adapted. Among the most typical situations activating defensive behavior are predator-prey interactions, when the crucial problem for most species is the effective recognition and avoidance of predators. Both ethology and comparative psychology have, for a long time, demonstrated an intense interest in various defensive behavior patterns, especially this pattern of "recognition and avoidance."

A number of recent ethological studies suggest a very precise and apparently adaptive relationship between specific stimuli or situations and the nature of the defensive response of a given species. Many observations have supported the hypothesis that animals can recognize their natural predators and respond to them by species-specific passive or active avoidance behavior, in most cases independently of prior experience (Arnold \& Bennett, 1984; R. J. Blanchard \& D. C. Blanchard, 1971; Ewert \& Traud, 1980; Herzog \& Schwartz, 1990; Hinde, 1954; Hirsch \& Bolles, 1980; Kruuk, 1976; Owings \& Coss, 1977).

\footnotetext{
This study was supported by a grant from the Hungarian Academy of Sciences (No. 2315/91). The authors' mailing address is Department of Ethology, L. Eötvös University, H-2131 Göd Jávorka u.14, Hungary.
}

Nevertheless, a number of studies have shown that in addition to innate abilities, learning plays an important role in the development of an adaptive defense system during the individual's life (Csányi, 1985; Curio, Ernst, \& Vieth, 1978; Schleidt, Shalter, \& Carawan, 1983). Various conceptions of this process have been published, some of these embedded in "general theory of learning" by the various psychological schools. But recently the refinement of this view was made possible by ethological approaches. Bolles (1970) assumed that many situation-specific differences are due to the relative availability of competing responses. Csányi $(1985,1986)$ modified Bolles's (1970) classic species-specific defensive reaction (SSDR) model (i.e., hierarchical arrangement of defensive behaviors), applying the concept of the species-specific key stimulus (SSKS), and suggested a simple model for predator recognition and learning processes. In this conception, the rapidity of acquisition (i.e., the difficulty of task) depends on the degree to which the expected response (e.g., avoidance) is compatible with the animal's repertoire (Anisman \& Wahlsten, 1974). According to another, similar approach presented later by R. J. Blanchard and D. C. Blanchard (1989a), the various defensive patterns precisely reflect the relevant features of eliciting threat stimuli in accordance with "relevance" or "belongingness" (Garcia, 1990). Thus, in a given situation, the defensive reactions are influenced by changes in the level of fear. As an alternative approach to this "response selection," Fanselow and Lester (1988) suggested the predatory imminence continuum (PIC) model. According to this model the predator-prey relationship can be described as a continuum, in which different defensive behaviors are most successful at different points in the sequence of predation. 
Several experiments have been carried out in order to establish the characteristic features of predators that elicit innate or learned species-specific reactions. The results show that a predator's odors and the sight of a predatorlike model elicit some (often selective) defensive behaviors from rodents and other mammalian species (D. C. Blanchard \& R. J. Blanchard, 1990; Catarelli \& Vigouroux, 1981; Dickman \& Doncaster, 1984; Henessey \& Owings, 1978). Beyond these, the role of eyespot-like patterns as fear-eliciting stimuli was confirmed in crustaceans (O'Brien \& Dunlap, 1975), birds (Curio, 1975; Gagliardi, Gallup, \& Boren, 1976; Jones, 1980; Scaife, 1976a, 1976b), mammals (Coss, 1978), and fish (Coss, 1979). Predator recognition and avoidance learning in paradise fish were studied in our laboratory (Altbacker \& Csányi, 1990; Csányi, 1985, 1986; Csányi, Csizmadia, \& Miklósi, 1989; Csányi \& Gervai, 1986; Csányi \& Lovász, 1987). Csányi (1986) found that using a passive avoidance conditioning paradigm, the presence of a simple dummy with two horizontally arranged eye-like spots is itself enough to activate a passive avoidance response, while a single spot or two vertically arranged spots proved to be less effective in eliciting the avoidance response despite the fact that the unconditioned stimulus (delivered shock) was the same. In another experiment, Altbacker and Csányi (1990) found that the large striking eyes of the predator (pike) have a direct role in eliciting the species-specific defense reaction of fin erection.

In light of these studies, it seems that the schema of two facing eyes has a broad, cross-species generality in meaning. The most plausible meaning is that two staring eyes suggest that one is being watched (Coss, 1991). Recognition of this may be important to the survival of potential prey. Presenting a number of examples of the evolutionary persistence of innate antipredator behaviors, Coss (1991) stated that the specific schema of two facing eyes embedded within a variety of backgrounds appears to be one of the most salient and invariant cues that promote individual recognition.

However, in some experiments with laboratory rodents, there were no or only barely detectable reactions to a predator or its odors (Chiszar, 1975; Lester \& Fanselow, 1985; Weldom, Divita, \& Middendorf, 1987). For wild rodents, reactions to discrete threatening stimuli such as a living predator are intense and show minimal intersubject variability. These highly adequate, immediate reactions might be maintained by natural selection. It is a wellknown phenomenon that some adaptive traits degenerate during domestication and that the differences are due to quantitative threshold shifting determined by genetic changes (Price, 1984; Smith, 1978). Thus, the léss expressed defensive reactions observed in naive laboratory rodents may be due to the long-term artificial selection against squealing and biting in response to human contact (R. J. Blanchard \& D. C. Blanchard, 1989b). Therefore, it seemed necessary for us to use close descendants of wild mice as subjects in our experiment.
In the present experiment, we examined the possible threatening aspects of various light-spot models in passive avoidance learning by the wild house mouse. Shuttlingactivity parameters provided simple measures of potentiation of the effects of a model by mild shock.

\section{METHOD}

\section{Subjects}

The subjects were 80 male and 80 female wild house mice (Mus musculus domesticus). They were the first generation of a parental population (consisting of 8 males and 8 females) trapped at three locations in a suburb of Budapest. The parents were housed as pairs in standard laboratory cages, and the offspring were caged with them until weaning at 24-28 days of age. After weaning, the offspring were separated according to sex (4-6 subjects in a cage). The cages were cleaned out every week; the shavings were replaced, but the nests containing pups in parental cages were left undisturbed. Pellet food (standard laboratory diet) and water were available ad lib. The temperature was kept at $18^{\circ}-24^{\circ} \mathrm{C}$. All the mice were between 60 and 90 days old at the time of the experiments. They were all marked individually with a small cut in the ear.

\section{Apparatus}

The experimental chamber was a white plastic shuttlebox, measuring $50 \times 15 \times 35 \mathrm{~cm}$, with a grid floor. Stainless steel rods were $2 \mathrm{~mm}$ in diameter and $9 \mathrm{~mm}$ apart. The box was divided into two compartments (compartments 1 and 2) by a white plastic wall that contained a 3-cm-diam circular gate $2 \mathrm{~cm}$ above the floor. Shuttling activity was monitored by an infrared photoelectric device located in the gate. This device served as a trigger for a train of electricshock pulses controlled by movement of the mouse. When the mouse left compartment 2 , the shocks delivered through the floor (20-msec trains of $500 \mathrm{~Hz} \mathrm{ac}, 0.1 \mathrm{~mA}$, every $0.2 \mathrm{sec}$ ) ceased automatically. The parameters of shuttling activity, such as the latency of the first crossing through the gate, the number of crossings, and the total amount of time spent in each compartment during a 5-min trial were recorded automatically. After each animal was tested, the shuttlebox was cleaned out with a 5\%-hypochlorite and 5\%-detergent solution, and then dried thoroughly. The apparatus was illuminated through a green plastic filter by six fluorescent tubes $(20 \mathrm{~W})$ from above. Thus there was even light in the two compartments of the shuttlebox.

\section{Models}

In some treatments, various light-spot models were applied. They were mounted on a piece of white rectangular plastic $(15 \times 40 \mathrm{~mm})$. The simplest of the models was a small yellow-light lamp (light emitting diode: LED) $4 \mathrm{~mm}$ in diameter (one-light model; see Figure 1a). Next in the series were two similar yellow lamps (LEDs) arranged either horizontally (two-horizontal-lights model; see Figure $1 \mathrm{~b}$ ) or vertically (two-vertical-lights model; see Figure 1c). Center-to-center LED spacing was $24 \mathrm{~mm}$. The fourth type of model consisted of three similar yellow lamps (LEDs) arranged closely in a triangular shape (three-lights model; see Figure ld).

We assumed, on the basis of results from previous experiments with paradise fish (Csányi, 1986), that the horizontally arranged two small yellow lights showed some similarity to the eye-spot patterns that represent perceptual cues important for predator avoidance.

\section{Procedure}

Two days prior to training, mice living in the same cage were placed together in the apparatus for $90 \mathrm{~min}$. On the following day (the day preceding Day 1 of training) they were placed in the shuttlebox individually for $10 \mathrm{~min}$. Neither electric shock nor manipulations with various models were applied. Twenty-four hours later 
(a)
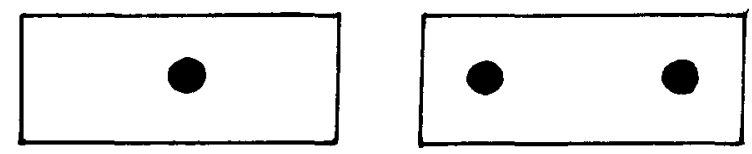

(C)

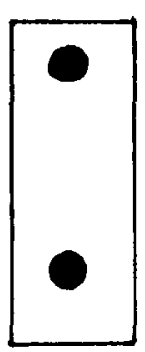

(d)

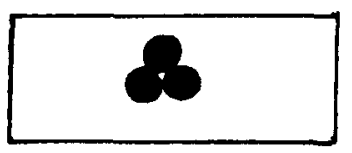

$\stackrel{1 \mathrm{~cm}}{\stackrel{2}{\longrightarrow}}$

Figure 1. Various models used in the experiment.

training began. A session occurred on each of 5 consecutive days: Once a day, the mice were placed individually in the empty starting (1) compartment for $5 \mathrm{~min}$, in the presence or absence of various models accompanying (or not) shocks in the other (2) compartment. The parameters of shuttling activity were recorded.

\section{Experimental Groups}

To examine the effect of various light-spot patterns on shuttling activity, 160 mice were divided into eight equal-sized groups ( $n \mathrm{~s}=$ 20 ), which were balanced with respect to sex. In all groups, a rectangular piece of plastic $(15 \times 40 \mathrm{~mm})$, either with or without one or more LEDs, was mounted on the wall of compartment 2 facing the gate, $4 \mathrm{~cm}$ above the floor.

During the 5 consecutive training days the groups received the following treatments: Group A-neither footshocks nor model. Group B-footshocks in compartment 2, but no model. Group C- no footshocks, but with the "one-light model" in compartment 2 . Group D-no footshocks, but with the "two-horizontal-lights model" in compartment 2. Group E-footshocks and the "one-light model" in compartment 2. Group F-footshocks and the "twohorizontal-lights model"' in compartment 2. Group G-footshocks and the "two-vertical-lights model" in compartment 2. Group $\mathrm{H}-$ footshocks and the "three-lights model" in compartment 2.

\section{RESULTS}

First, one-way analyses of variance (ANOVAs) were carried out to compare shuttling activity of the eight groups on the day prior to training. The latency to cross into compartment $2[F(7,152)=0.31]$, the number of crossings $[F(7,152)=1.71]$, and the time spent in compartment 2 $[F(7,152)=1.46]$ were not found to be significant.

The effects of different variables (treatment, sex, trials) on performance during training of all groups $(\mathrm{A}-\mathrm{H})$ were analyzed in a single large three-way ANOVA with repeated measures.

With regard to latency (see Figure 2), this analysis indicated significant main effects for the trials $[F(4,720)=$ $2.67, p<.05$; lower latency on Day 1] and treatment $[F(7,720)=12.47, p<.001$; higher latency in the "complete" (E-H) groups]. Neither the main effects of sex $[F(1,720)=0.01]$ nor any interactions were found to be significant.

The time spent in compartment 2 was analyzed by a three-way ANOVA. The main effects of treatment $[F(7,720)=75.8, p<.001$; more time spent in compartment 2 if there was no shock] and sex $[F(1,720)=$ $14.8, p<.001$; females spent less time in compartment 2] were found to be significant. But neither the main effect of trials $[F(4,720)=0.75]$ nor any interactions were found to be significant.

Regarding the number of crossings, the three-way ANOVA showed significant main effects for both treatment $[F(7,720)=9.64, p<.001 ;$ more crossings in

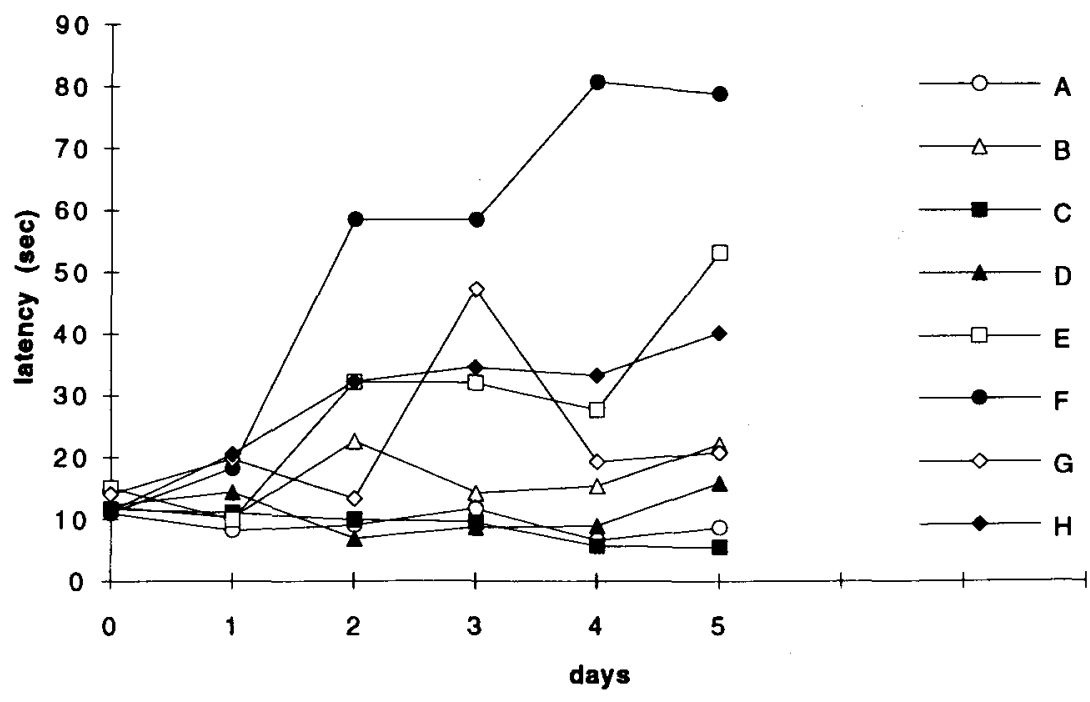

Figure 2. Latency across trials in all groups (A-H). Group means are shown. 
shocked groups $]$ and sex $[F(1,720)=5.33, p<.05$; females crossed the gate more frequently]. The main effects of trials $[F(4,720)=0.93]$ and the interactions were not significant.

As these results show, prior to training, all the groups behaved identically in the shuttlebox, but both shock delivered and the presence of the various models influenced all three parameters of shuttling activity. After the overall analysis, some specific planned comparisons of the groups were carried out.

\section{Latency}

On Day 1 of training, significant differences were not found in the average latency of the eight groups $[F(7,152)=1.82]$, in contrast to the findings for Days $2-5[F(7,152)=2.78, p<.01 ; F(7,152)=2.33, p<$ $.05 ; F(7,152)=4.59, p<.001 ; F(7,152)=4.02, p<$ .0011 . As Figure 2 shows, the essence of the difference is that the mice in Groups E-H (especially in Group F) tended to cross significantly later than did the mice in the other groups. While the one-way ANOVAs did not show significant differences between the eight groups on either the day preceding the training or on Training Day 1 (see Figure 3), considerable differences were found between the groups in the average latencies calculated from the individual averages of the last four trials $[F(7,152)=5.5$, $p<.001]$. As Figure 3 shows, post hoc comparisons of the means by the Duncan range test $(p<.05)$ revealed four different, partly overlapping ranges.

Comparing the four "complete" groups $(\mathrm{E}-\mathrm{H})$, the effects of the various models and the trials were analyzed by a two-way ANOVA using latency as the repeated measure. Both the main effects of various models $[F(3,380)=$ $5.34, p<.005$; the mice in Group $\mathrm{F}$ tended to cross later] and the trials $[F(4,380)=2.64, p<.05$; the mice tended to cross later on Days 2-5] proved to be significant. The interaction was not found to be significant. Figure 4 shows the post hoc comparisons of the means by the Duncan range test $(p<.05)$.

\section{Time Spent in Compartment 2}

Significant differences were found on Day $1[F(7,152)=$ $10.90]$, Day $2[F(7,152)=17.85]$, Day $3[F(7,152)=$ 14.21], Day $4[F(7,152)=17.82]$, and Day $5[F(7,152)=$ 15.35 ] ( $p<.001$ in each case). As Figure 5 shows, the "no-shock" groups (A, C, and D) spent a large amount of time in compartment 2 on all trials, whereas the average time of the shocked groups decreased significantly.

Data from the four "complete" groups (E-H) were analyzed by a two-way ANOVA (model $x$ trials) using the time as a repeated measure. Only the main effect of models $[F(3,380)=7.54, p<.001$; the mice in Group $F$ spent less time in compartment 2] was found to be significant.

\section{Number of Crossings}

The daily number of crossings made by the eight groups were analyzed by one-way ANOVAs, and the following results were obtained: on Day $1, F(7,152)=3.44, p<$

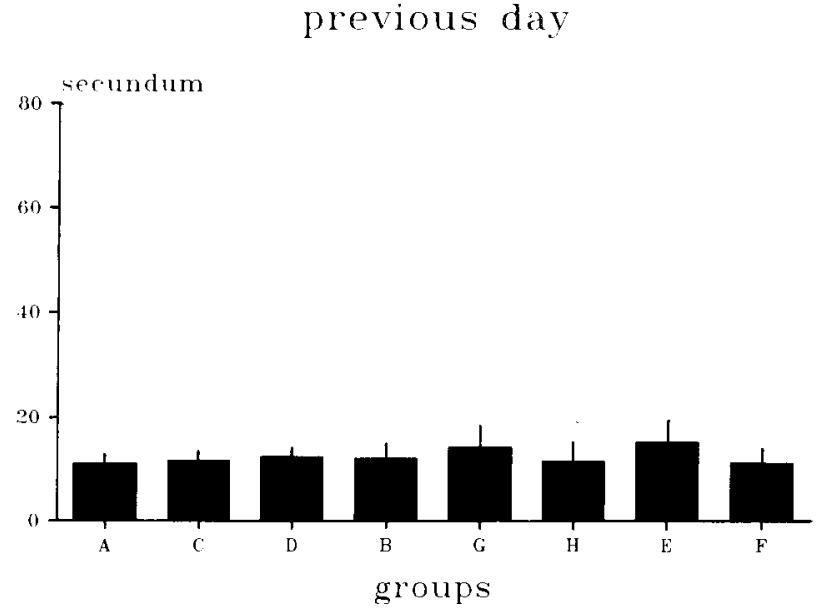

first day
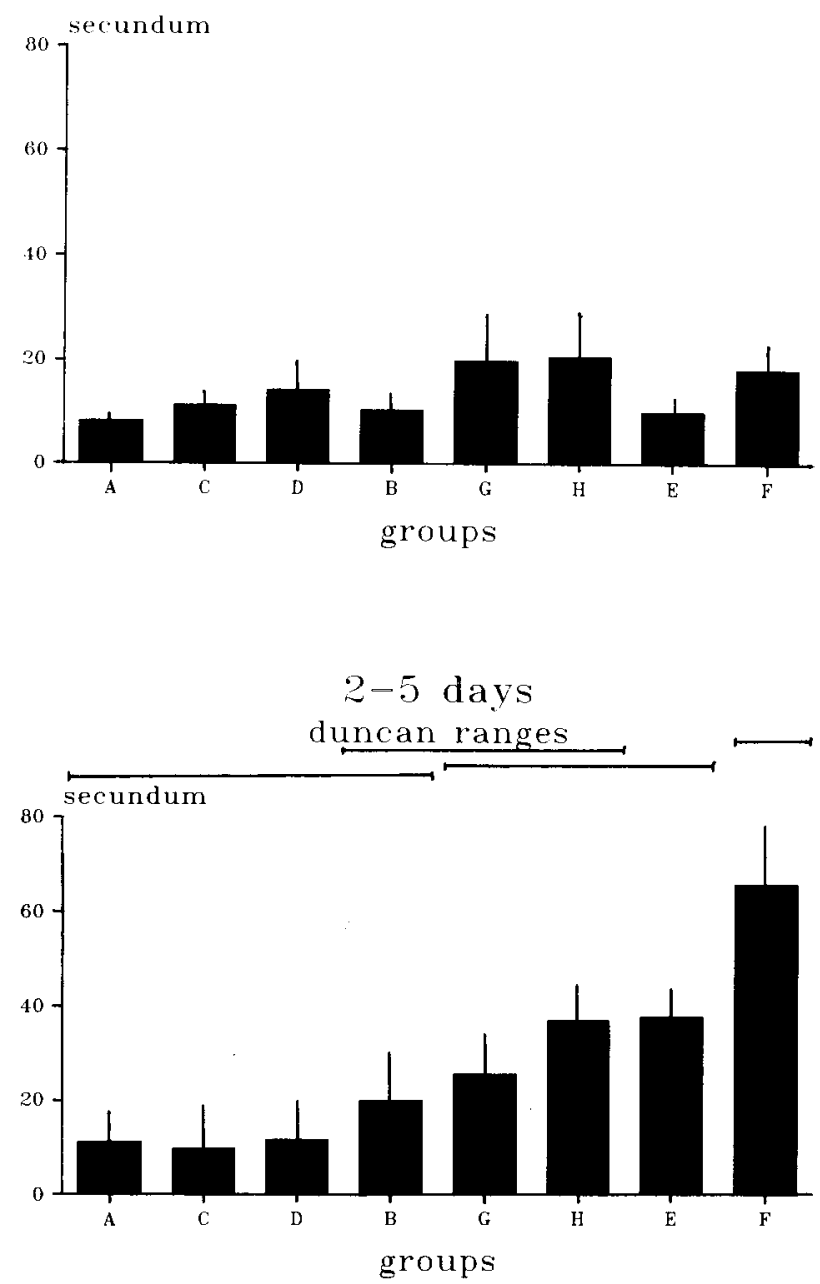

Figure 3. Latency calculated from the individual data in the various groups. Bars represent means $(+S E)$; Duncan ranges are also shown. 


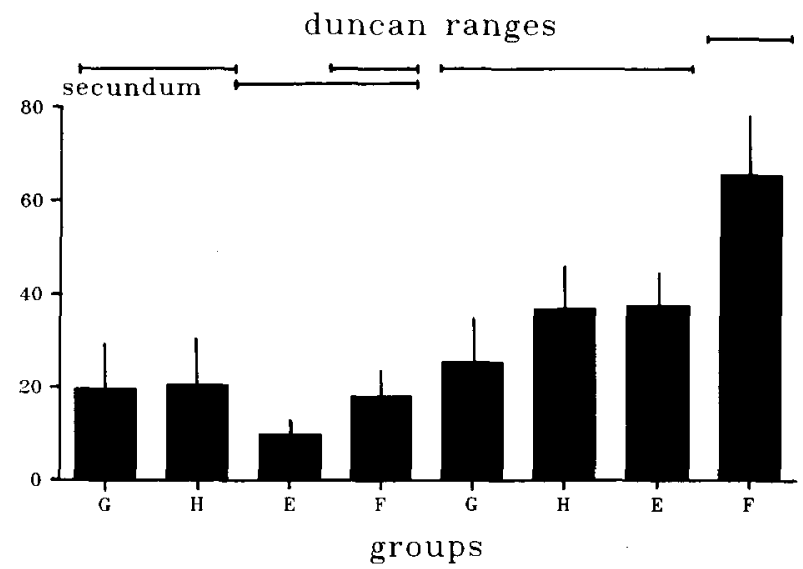

first day

Figure 4. Latency calculated from the individual data in the four "complete" groups. Bars represent means $(+S E)$; Duncan ranges are also shown.

.005 (i.e., the shocked groups showed more crossings, especially Group B); on Day $2, F(7,152)=1.11$, n.s.; on Day $3, F(7,152)=1.9$, n.s.; on Day $4, F(7,152)=$ $2.59, p<.05$; and on Day $5, F(7,152)=2.32, p<.05$. Group means during trials are shown in Figure 6.

\section{DISCUSSION}

The aim of this paper was to demonstrate the potentiation of the provocative properties of horizontally arranged yellow lights by using mildly aversive footshock. Initially, there was no difference in latency between groups. How-

ever, from the second trial onward, in the groups trained with footshock in the presence of one of the models, a significant increase in the latency to enter compartment 2 was observed. If either footshock or a model was not present (Groups B-D), there was no change in performance as compared with that of controls (Group A). In other words, the mild electric shock alone was insufficient to elicit avoidance responses and the models had feareliciting properties only in the presence of mild pain.

The four groups that had models paired with shock (Groups E-H) were not equivalent. Footshock paired with two horizontally arranged light-spots proved to be more efficient in eliciting changes in shuttling activity (i.e., avoidance) than did the other models.

The amount of time spent in the shocked compartment indicates readiness to escape. The no-shock groups (A, $C$, and D) did not change in the time they spent in the shock chamber, which didn't differ significantly from the .50 probability level $(150 \mathrm{sec})$. Groups that received footshock showed a marked reduction in this parameter (i.e., the readiness to escape increased). But there were significant differences among these groups in this measure; the two horizontal lights paired with footshock elicited the highest inclination to escape.

Usually number of crossings are related to the tendency to explore. There was increased exploratory activity shown by the shock groups during the first trial (Day 1). The frequency of crossings decreased after the second trial (Day 2); exploration was followed by avoidance.

There were considerable differences between sexes in several of the parameters of shuttling activity. Besides more crossings, females spent less time in compartment 2 than did males. According to our observations, this was so because males, instead of returning to compartment 1 ,

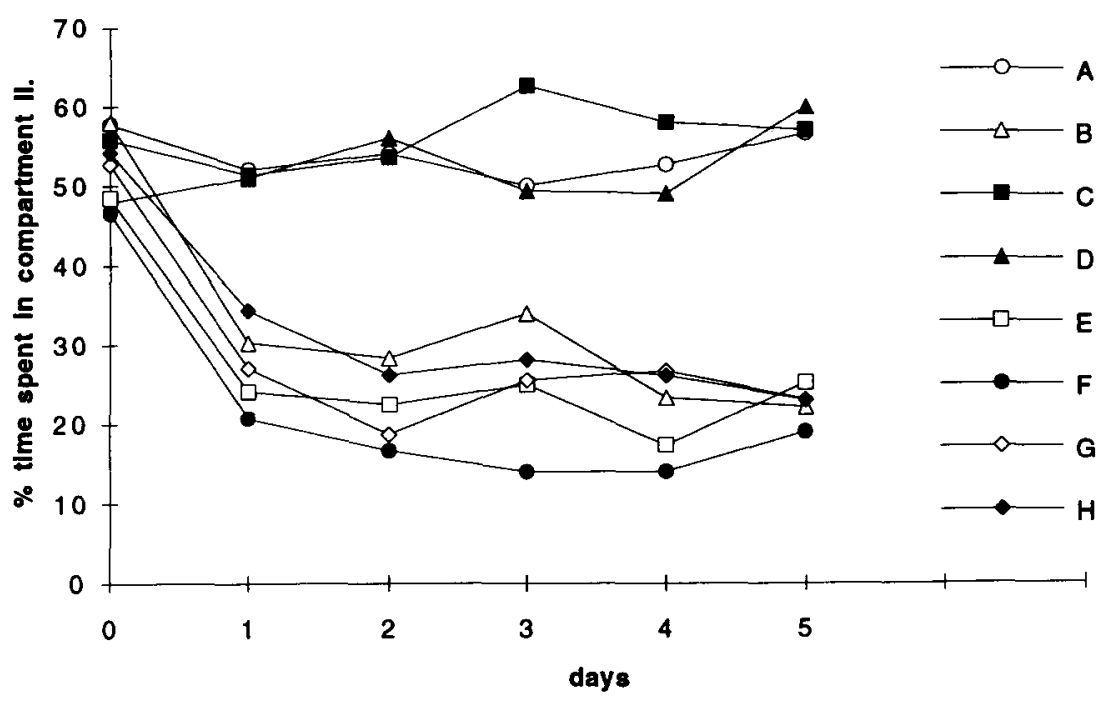

Figure 5. Time spent in dark during various treatments. Group means are indicated. 


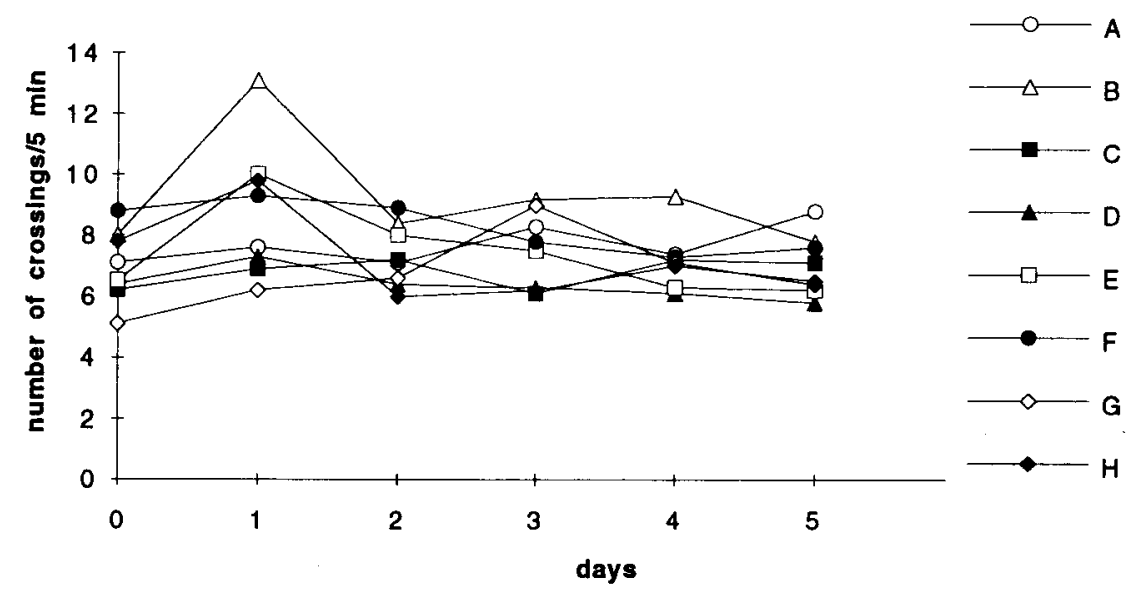

Figure 6. The number of gate crossings made during various treatments. Group means are indicated.

tried to escape from compartment 2 by jumping along the wall more frequently than did females. There were no significant sex-related differences in step-through latency.

Summarizing these results, we can draw as a conclusion that the presence of two light-spots arranged in horizontal fashion results in an increased probability of passive avoidance. Since the shocks did not make the animals less active (in comparison with the no-shock groups), an interpretation based on inhibition of activity can be excluded. Two factors may be invoked in explanation of the observed differences in shuttling activity caused by the presence of the various models. One is that there is an additive effect (Warren, 1953); that is, the more lights presented, the higher the luminosity and the more aversive the situation. Second is that there are ecologically relevant, "meaningful"' schemata (Coss, 1978, 1979, 1991; Csányi, 1985, 1986). Learning may be sensitive to the number and position of the lights because the horizontally arranged yellow light-spots might bear some similarity to two facing eyes.

The former possibility, that of increased learning due to additive effects, may be excluded, since the tendency to escape and the acquisition of learning on the part of Group H showed significant reduction as compared with Group F. The three-lights model elicited less fear than did the eye-like schema of two. The comparison of Groups $\mathrm{G}$ and $\mathrm{F}$ supports the suggestion that an eyespot-like configuration represents a threat; changing the spatial arrangement of the yellow lights from horizontal to vertical considerably decreased the effectiveness of the stimulus.

In addition to the traditional evaluation of shuttling activity, we can put the results of experiments carried out in restricted laboratory conditions into a broader, ethologically oriented theoretical framework. According to several studies, rodents innately freeze in response to the presence of predators, perhaps because the reduction in movement decreases the probability of detection. The use of shocks appears to be a valid way of modeling predation because shock elicits species-specific antipredatory behavior such as freezing (Fanselow, 1980; Fanselow \& Bolles, 1979).

In the course of avoidance conditioning, if certain aspects of the environment are less strongly associated with aversive stimuli, animals will gravitate toward those areas and freeze there. For an individual to select an adequate response, the predictability of the contextual stimuli is very important. In our experiments, in order to avoid painful situations, animals had to recognize stimuli that predicted a high imminence of shock. The strength of predictability in a stimulus is determined by biological predispositions, and threatening stimuli can thus be separated from "meaningless" ones.

The basic finding of this paper is that the two horizontal yellow lights are not neutral, and that changing the overall context from nonthreatening (no shock) to threatening (shock) enhances the aversive properties of this pattern. Our results show that this "specificity" can be revealed even in the case of such a simple stimulus as a "predator" reduced to two horizontal light spots. The existence of ecologically important stimuli that have perceptual significance for a variety of species cannot be interpreted without a discussion of phylogenetical background and the broader neurobiological, ecological, and ethological context.

\section{REFERENCES}

AltBaCKer, V., \& CsánYI, V. (1990). The role of eyespots in predator recognition and antipredatory behaviour of the paradise fish, $\mathrm{Mac}$ ropodus opercularis L. Ethology, 85, 51-57.

ANISMAN, H., \& WahLSTEN, D. (1974). Response initiation and directionality as factors influencing avoidance performance. Journal of Comparative \& Physiological Psychology, 87, 1119-1128.

ARNOLD, S. J., \& BENNETT, A. F. (1984). Behavioural variation in natural populations. ШI: Antipredator displays in the garter snake Thamnopis radix. Animal Behaviour, 32, 1108-1118.

BlanchaRD, D. C., \& BlanchaRD, R. J. (1990). Effects of ethanol, 
benzodiazepines and serotonin compounds on ethopharmacological models of anxiety. In N. McNaughton \& G. Andrews (Eds.), Anxi ety (pp. 188-199). Otago, New Zealand: University of Otago Press.

Blanchard, R. J., \& BLANCHARD, D. C. (1971). Defensive reactions in the albino rat. Learning \& Motivation, 2, 351-362.

BlanchaRD, R. J., \& BlanchaRD, D. C. (1989a). Antipredator defensive behaviors in a visible burrow system. Journal of Comparative Psychology, 103, 70-82.

BlanCHARD, R. J., \& BlanCHARD, D. C. (1989b). Attack and defense in rodents as ethoexperimental models for the study of emotion. Psychopharmacology \& Biological Psychiatry, 13, 3-14.

Blanchard, R. J., Blanchard, D. C., \& Hori, K. (1989). Ethoexperimental approaches to the study of defensive behavior. In R. J. Blanchard, P. F. Brain, D. C. Blanchard, \& S. Parmigiani (Eds.), Ethoexperimental approaches to the study of behavior (pp. 114-136) Dordrecht: Klüwer.

Bolles, R. C. (1970). Species-specific defense reactions and avoidance learning. Psychological Review, 77, 32-48.

Catarelli, M., \& Vigouroux, M. (1981). Evaluation of emotional reactions of the rat elicited by biologically meaningful odorants during operant behavior. Physiology \& Behavior, 27, 445-456.

ChISZAR, D. (1975). Laboratory mice (Mus musculus, C57/BL 6J) do not exhibit fear in the presence of a rattlesnake. Bulletin of the $P_{s y-}$ chonomic Society, 6, 377-378.

Coss, R. G. (1978). Perceptual determinations of gaze aversion by the lesser mouse lemur, Microcebus murimus: The role of two facing eyes. Behaviour, 64, 248-270.

Coss, R. G. (1979). Delayed plasticity of an instinct: Recognition and avoidance of two facing eyes by the jewel fish. Developmental Psychobiology, 12, 335-345.

Coss, R. G. (1991). Evolutionary persistence of memory-like processes. Concepts in Neuroscience, 2, 129-168.

CSÁNYI, V. (1985). Ethological analysis of predator avoidance by the paradise fish. (Macropodus opercularis L.): I. Recognition and learning of predators. Behaviour, 92, 227-240.

CsánYI, V. (1986). Ethological analysis of the predator avoidance by the paradise fish (Macropodus opercularis L.): II. Key stimuli in avoidance learning. Animal Learning \& Behavior, 14, 101-109.

Cś́nyi, V., Csizmadia, G., \& Miklósi, A. (1989). Long term memory and recognition of another species in the paradise fish. Animal Behaviour, 37, 908-911.

CSÁNYI, V., \& GeRVAI, J. (1986). Behavior-genetic analysis of the paradise fish (Macropodus opercularis): II. Passive avoidance learning in inbred strains. Behavior Genetics, 16, 553-557.

CsÁNYI, V., \& LoVÁsz, F. (1987). Key stimuli and the recognition of the physical environment by the paradise fish (Macropodus opercularis). Animal Learning \& Behavior, 15, 379-381.

CuRIo, E. (1975). The functional organization of antipredator behaviour in the pied flycatcher: A study of avian visual perception. Animal Behaviour, $23,1-45$.

Curio, E., ERNST, K., \& VIETH, W. (1978). The adaptive significance of avia mobbing: II.Cultural transmission of enemy recognition in blackbirds: Effectiveness and some constraints. Zeitschrift für Tierpsychologie, 48, 184-202.

Dickman, C. R. , \& Doncaster, C. P. (1984). Responses of small mammals to red fox (Vulpes vulpes) odor. Journal of Zoology, 204, 521-532.

EWERT, J. P. \& TRAUD, R. (1980). Releasing stimuli for anti-predator behaviour in the common toad (Bufo bufo). Behaviour, 68, 170-180.

FANSELOW, M. S. (1980). Conditional and unconditional components of postshock freezing. Pavlovian Journal of Biological Science, 15, 177-182.
Fanselow, M. S., \& Bolles, R. C. (1979). Triggering of the endorphin analgesia reaction by a cue previously associated with shock: Reversal by naloxone. Bulletin of the Psychonomic Society, 14, 88-90.

Fanselow, M. S., \& LeSTER, M. S. (1988). A functional behavioristic approach to aversively motivated behavior: Predatory imminence as a determinant of the topography of defensive behavior. In R. C. Bolles \& M. B. Beecher (Eds.), Evolution and leaming (pp. 185-210). Hillsdale, NJ: Erlbaum.

Gagliardi, G. J., GalluP, G. G., \& Boren, J. L. (1976). Effects of different pupil to eye size ratios on tonic immobility in chickens. Bulletin of the Psychonomic Society, 8, 58-60.

GaRCIA, J. (1990). Learning without memory. Journal of Cognitive Neuroscience, 2, 282-305.

Hennessy, D. F., \& OWIngs, D. H. (1978). Snake species discrimination and the role of olfactory cues in the snake-directed behaviour of the California ground squirrel. Behaviour, 65, 115-124.

Herzog, H. A., \& SChWARTz, J. M. (1990). Geographical variation in the anti-predator behaviour of neonate garter snakes, Thamnopis sirtalis. Animal Behaviour, 40, 597-601.

HINDE, R. A. (1954). Factors governing the changes in strength of a partially inborn response, as shown by the mobbing behaviour of the chaffinch (Fringilla coelebs): The nature of the response and the examination of its course. Proceedings of the Royal Society Bulletin, 142, 306-331.

HiRSCH, S. M., \& Bolles, R. C. (1980). On the ability of preys to recognize predators. Zeitschrift für Tierpsychologie, 54, 71-84.

JONES, R. (1980). Reactions of male domestic chicks to two-dimensional eye-like shapes. Animal Behaviour, 28, 212-218.

KRUUK, H. (1976). The biological function of gull's attraction towards predators. Animal Behaviour, 24, 146-153.

LESTER, L. S., \& FANSELOW, M. S. (1985). Exposure to a cat produces opioid analgesia in rats. Behavioral Neuroscience, 99, 756-759.

O'Brien, T. J., \& DunlaP, W. P. (1975). Tonic immobility in the blue crab (Callinectes sapidus, Rathburn): Its relation to threat of predation. Journal of Comparative Physiology \& Psychology, 98, 86-94.

OwINGs, D. H., \& Coss, R. G. (1977). Snake mobbing by California ground squirrels: Adaptive variation and ontogeny. Behaviour, 62, 50-69.

PrICE, E. O. (1984). Behavioral aspects of animal domestication. Quarterly Review of Biology, 59, 1-32.

SCAIFE, M. (1976a). The response to eye-like shapes by birds. I. The effect of context: A predator and a strange bird. Animal Behaviour, 24, $195-199$.

ScaIFE, M. (1976b). The response to eye-like shapes by birds. II. The importance of staring, pairedness and shape. Animal Behaviour, 24, 200-206.

Schleidt, W. M., Shalter, M. D., \& Carawan, T. C. (1983). The effect of spatial context on habinuation to a predation model. Zeitschrift für Tierpsychologie, 61, 67-70.

SMITH, R. H. (1978). Selection for shuttle avoidance in wild Mus musculus. Behavior Genetics, 8, 269-274.

WARREN, J. M. (1953). Additivity of cues in visual pattern discriminations by monkeys. Journal of Comparative Physiology \& Psychology, 46, 484-486.

Weldon, P. J., Divita, F. M., \& Middendorf, G. A. (1987). Responses to snake odors by laboratory mice. Behavioral Processes, 14, 137-146.

(Manuscript received April 27, 1992; revision accepted for publication May 21, 1993.) 